\title{
The Differentiation of Phonological and Morphological Intrusion for the Two-Dimensional Orthography
}

\author{
Yang Lee ${ }^{1,2^{*}}$, Claudia Carello \\ ${ }^{1}$ Department of Psychology, Gyeongsang National University, Jinju-si, South Korea \\ ${ }^{2}$ Department of Psychology, University of Connecticut, Storrs, CT, USA \\ Email: "yangleepsy@gamil.com
}

Received 8 July 2016; accepted 6 August 2016; published 9 August 2016

Copyright (C) 2016 by authors and Scientific Research Publishing Inc.

This work is licensed under the Creative Commons Attribution International License (CC BY). http://creativecommons.org/licenses/by/4.0/

(c) (7) Open Access

\section{Abstract}

The writing systems have been developed by regard that how sound is written to express phonology in letters. So to interpret the written words, the phonological orthography is deemed to have serious contribution. In researches, the decoding processes of phonology have been concerned, proposing some theories as orthographic depth hypothesis, and phonological primary principle. However the other aspect of orthography has been raised with regard of how to reserve morphology in writing. Also to understand the written words, the analysis of the morphological orthography is viewed to help readers. So in researches, some of morphological effects have been analyzed. This study presupposed two-dimensional category of phonology and morphology to set various writing systems. Attempting to confirm the two dimensions, an experiment was designed to analyze both of phonological and morphological effect. For the purposes, the intrusion effect of phonology or morphology was proposed as what is sensitive to working of the two dimensions. This study observed the intrusion of phonology which influenced on the semantic task which required judging whether same or different in meaning between prime and target. And also the intrusion of morphology was observed when judging sounds between prime and target was required. This study sampled Korean and Chinese words both of which belong to Korean language, and each of which is posited by this study to be distributed differently in the two dimensions of phonology and morphology. The analysis of the results showed both of the sound and meaning intrusion, concluding that Korean writing system kept the two-dimensional category of phonology and morphology. Therefore this study pointed out the limit of one-dimensional category hitherto accepted, where each of the phonological and morphological orthography is posed at each of the two extremes in one-dimension, requiring the further tests on the other languages to make generalization of the two-dimensional category of phonology and morphology proposed and supported by

${ }^{*}$ Corresponding author. 


\section{this study.}

\section{Keywords}

\section{Phonology, Morphology, Intrusion, Orthography}

\section{Introduction}

What are defined as the writing system are various over worldwide. To categorize them, varieties of criteria have been attempted. What is common across the attempts are the phonological dimension and morphological dimension which are to embed a pattern of interaction for a writing system (Lee, 1992; see also Lee, 2014 for experimental data). However, owing to theories one of them was regarded as a primary dimension; some concerned to the phonological dimension, but others to the morphological dimension. For phonological primacy, the orthographic depth hypothesis was proposed (Katz \& Frost, 1992) and supported by some experimental researches. The theory defined the orthographic depths as the level of transparency between orthography and phonology; if it is shallow (transparent), the correspondence between orthography and phonology is nearly one to one. To test the theory, various writing systems were conditioned and the phonological effect was observed in word recognition. To be summarized, the strong phonological effect was shown in the shallow depth of the writing systems as Spanish, and Serbo-Croatian, and the reverse was found in the deep orthography as Hebrew and English (Frost, Katz, \& Bentin, 1987). With this frame Lee el al. (i.e. Lee, Moreno, Carello, \& Turvey, 2013) tested the phonological primacy with the manipulation of phonological rule within Korean languages (see also Lee et al., 2006 for similar design), not between languages, and also Rimzhim (2014) attempted to test the effect of phonological rules with Indian language (see also Rimzhim, Katz, \& Fowler, 2013 for general discussion of Indian language).

Also related to phonological effect, Lukatela and Turvey (1994) proposed the phonological precedence with evidences for phonological coding to be precedent on word recognition (see also Lukatela, Eaton, Sabadini, \& Turvey, 2004 for followed up test). Further, Perfetti (2011) suggested the universal phonological principle, saying that reading engages phonology at the earliest moment and smallest unit allowed by writing system (see also Perfetti, Zhang, \& Berent, 1992 for general discussion).

The line of the above analysis is limited to concern only to phonological dimension. Morphological dimension should be regarded. Some the schemes of the writing systems as Hill (1967) and DeFrancis (1989) added the morphological dimension to categorize writing systems. According to Lee (1995), either phonological or morphological dimension is not sufficient to explain properties of writing system (see also Jin, Lee, \& Lee, 2013 for more discussion). The two are independent to set up properties of writing system. Applying this position to the above orthographic depth hypothesis, what is limited is found in the premise as the morphological properties are dependent on the phonological ones, in other words as phonological depth is to correlate a level of morphological dimension. For example, Serbo-Croatian is phonologically transparent, accompanied with morphologically ambiguity, and English is phonologically opaque with morphologically clearness. However, Lee (2014) demonstrated to compare two schemes of one-dimensional category, shown as (1) in Figure 1 and two-dimensional category shown as (2) in Figure 1 (see also Lee, 2003 for original discussion).

Introducing Korean and Chinese to be applied to Figure 1, Korean character is known as an alphabetic system (see Gelb, 1963 for general discussion) where 14 consonants (for example $\neg / \mathrm{g} /$, L/n/, etc ) and 10 vowels ( $\mathrm{f} / \mathrm{a} /, \perp / \mathrm{o} /$, etc) are composed to make a sound unit of syllable (for example 간/gan) which is almost to be a unit of meaning (간/=lever/) to make various compound words (간 염/=lever-inflammation/) . So Korean character belongs to the phonemic system, but also leads to morphology (Lee, 1992). In contrast, Chinese character is not alphabetic system but is labeled as the logographic system (see Gelb, 1963 for general discussion), which has the syllable as the smallest unit, associated to meaning and attached to sound for a whole character (for example, 植/sig/=planting/). So Chinese character is to be the morphemic system (木/=plant) but also to have association of phonology to radical (直/sig/ or /zig/).

Discussing dimensions where to place Korean and Chinese, in one dimension, Chinese and Korean are mentioned to be different only in levels of phonological transparency; Chinese is placed to opaqueness, but Korean 
Phonologically

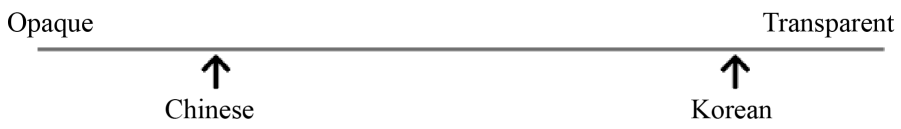

(1) One-dimensional category

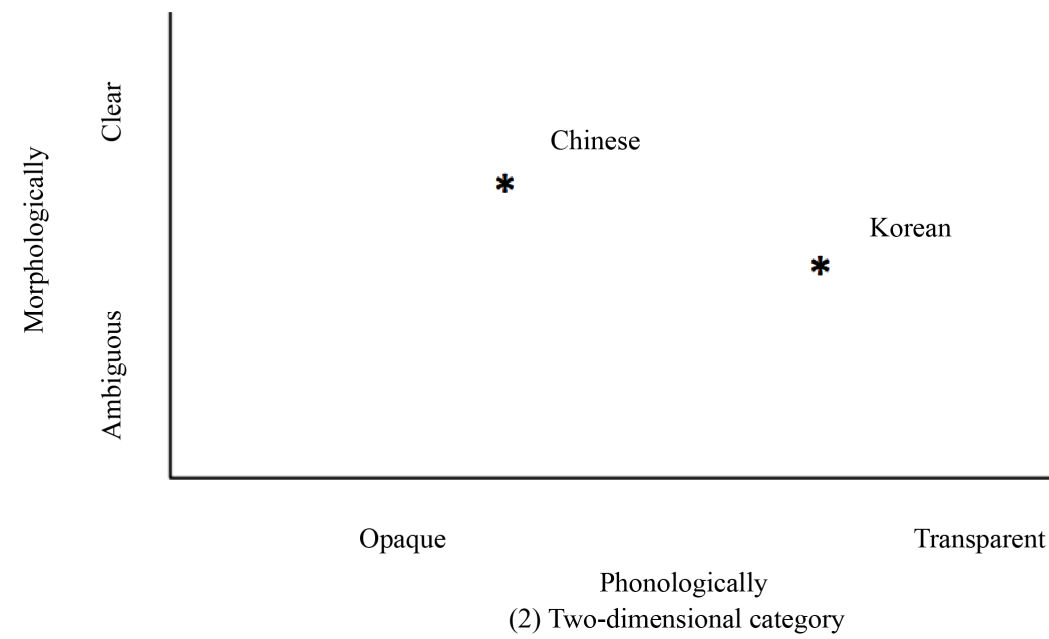

Figure 1. One-dimensional category for phonology (1) and Two-dimensional category for phonology and morphology (2) to set Korean and Chinese Character.

to transparence. The scheme is like the orthographic depth hypothesis. However applying two-dimension, Chinese and Korean are different both in levels of phonological transparency and morphological transparency. Differentiated from the orthographic depth, the scheme affords independence of phonology and morphology. So it is predicted, that if designed with manipulation of both variables of phonology and morphology, the effects of two variables are observed independently.

This study attempted to test the two independent dimensions of phonology and morphology, the same experiment which Jeong, Katz, Carello, and Lee (draft) designed to test the orthographic depth. This experiment was attended by only Korean, not sampled between languages, who have used two writing systems of Korean (called Hangul) and Korean Chinese (called Hanja). Hangul mainly utilizes an alphabetic orthography, and so each letter of Hangul has one sound (phoneme). Korean Chinese has been developed since a long ago, differentiated from Chinese in China in terms of pronunciation and meaning, so commented according to some scholars (Lee, 1992) that Korean Chinese was originated with the advent of Korean culture. This study is designed to observe how Hangul and Hanja are posited in phonological and morphological levels.

The reciprocal effects of phonology and morphology are incarnated by the intrusion effect. What is influenced in the decision about meaning by phonological properties is defined as the phonological intrusion. In contrast, what is influenced in the decision about sound by the morphological properties is defined by the morphological intrusion. In process of Hangul word which has phonological transparency, the phonological intrusion on decision about meaning is anticipated. However in process of Hanja word which has morphological conservation, the morphological intrusion on decision about sound is anticipated. This study tried to analyze process of Hangul and Hanja pairs, finding the intrusion effects of phonology and morphology, both of which are anticipated not only from phonological transparency of Hangul, but also from morphological transparency of Hanja, for the purpose that the two-dimensional category of orthography is supported. If both of the intrusions are found, it is posited that Korean writing system of Hangul and Hanja has two dimensions of phonology and morphology. Thus in order to test the intrusion effects of phonology and morphology, an experiment was designed.

\section{Experiment}

The experiment had observers presented on every trial two sequential printed items of prime and target. The first 
(the prime) was printed in Hangul; the second (the target) was a Hanja from the inventory of printed Chinese words known to Korean people. Thus, prime and target had no orthographic information in common. All prime words had two syllables and all target words consisted of only a single syllable. There were two tasks. In one, participants judged if the target had the "same sound" as the prime's first syllable, ignoring the meanings of both words. In the other task, participants judged if the target had the "same meaning" as the prime's first syllable, ignoring the phonology. Because many monosyllabic words of Korean language are polysemous, two-syllable prime words were chosen for the Hangul stimulus in order to make the meaning unambiguous.

It is predicted that decisions about meaning shows phonological intrusion, and also decisions about sound has morphological intrusion. Since process of Hanja requires lexical access to find the associated phonology and morphology. To observe intrusion effects, were manipulated three conditions for each of the two tasks: Subjects are to judge as a same meaning or a same sound. One of the conditions had prime and target differed on both their meaning and their sounds. So the condition required a response of "different/No" either for judgment on meaning or sound. In another condition, the two stimuli of prime and target had both a same meaning and a same sound, requiring "same/Yes" in either tasks. The last condition had two versions due to the task to require judgment on meaning or on sound. When the task required judging if the prime and target were same in meaning, the two stimuli had a same meaning with different sounds, requiring "same/Yes" in meaning. Thus, the different sound attempted to act as a spoiler to interfere with the positive decision judged on meaning. In contrast, for the task in which a same sound was judged, prime and target had a same sound with different meanings, requiring "same/Yes" in sound. Thus, the third condition was always one in which the stimulus dimension that was irrelevant to the task encouraged a competing response to the relevant stimulus (see Holender, 1992 for a general discussion).

The purpose of this manipulation was to determine if processing was affected by the irrelevant dimension. This is to be discussed as one of congruency effects (Holender, 1992). More intended, manipulating the congruency of prime and target pair, it is predicted that the intrusions both of phonology and morphology are observed since the process of Hangul and Hanja is worked by analyzing both of phonological and morphological orthography. Thus if the intrusion of phonology and morphology is found, the two-dimensional category of orthography is supported

\subsection{Method}

Participants: Thirty-eight students from a psychological class in Gyeongsang National University (in South Korea) participated as the part of their psychology course requirement. They are kept in protection for human subject regulated by Institute of Review Board of Gyeongsang National University. Their sights are normal or revised by eyeglass fitting. They are good at reading and writing Korean and Chinese characters included in the experimental stimuli. Nineteen participants were randomly assigned to each of two stimulus lists.

Design and stimuli: Each participant received the two tasks separately, each task taking up half the session; task order was counterbalanced across participants. In every pair, the prime was a two-syllable word printed in Hangul, and the target was a character of Hanja with a one-syllable pronunciation. In one task (sound-judgment task), participants were asked to respond, "Yes" (by key press) if the one-syllable target was pronounced the same as the first syllable of the two-syllable prime, without regard to meaning. In the other task (meaningjudgment task), participants were to respond, "Yes" if both prime and target had a same meaning, without regard to pronunciation. A subject was treated with 80 trials in each task, duplicated to 160 trials for 2 tasks in within subject variable design.

As introduced in Experimental purpose, the experimental design is shown with examples of stimuli in each of 3 conditions crossed with 2 tasks as Figure 2. The first condition of "No" response in both of the two tasks is the pair of stimuli in which the prime is 물건 [mul-geon] (material-one), and the target is 水 [su] (water). the second condition of "Yes" response in both of the two tasks is the pair in which the prime is 수도 [su-do] (water-pipe) and the target is 水 [su] (water). For one of the third condition, when the task was to judge 'same' meaning, the contrasting sounds of prime and target: prime 물통 [mul-tong] (water-basket) and target: 水 [su] (water) are paired. Here, the correct judgment "Yes" will be adversely influenced by the different pronunciations of prime and target if the irrelevant dimension intrudes into the decision process. For the other of the third condition, when the task was to judge "same" sound, prime 수식 [su-sig] (number-formula) and target: 水 [su] (water) are paired. Here, the correct judgment "same sound" may be adversely influenced by the different meanings. 




Task : Same Sound?

Prime

물건/mul-goen/(material-one)

수도/su-do/(water-pipe)

수식/su-sig/(number-formula)

$$
\begin{aligned}
& \text { Target } \\
& \text { 水/su/(water) } \\
& \text { 水/su/(water) } \\
& \text { 水/su/(water) }
\end{aligned}
$$



Relation of

Meaning, Phonology

$M \neq P \neq$

$\mathbf{M}=\mathbf{P}=$

$M \neq P=$

Figure 2. Stimulus examples for each condition in the experiment (Prime; Hangul - Target Hanja).

Each task had three conditions, only one of which differed between the two tasks. In the sound-judgment task, $25 \%$ of all stimulus pairs, i.e., 20 trials, were $\mathrm{M} \neq \mathrm{P}=$, i.e., different meanings but a same pronunciation between the first syllable of the prime and the target, requiring the response, "Yes", for example, in the English homophone pair, nighttime - knight. However, unlike the English example, the Hangul prime and Hanja target had no overlap in spelling because they were written in different scripts. In the meaning-judgment task, $25 \%$, i.e., 20 trials were replaced with stimulus pairs that had a same meaning but different pronunciations $(M=P \neq)$, requiring the response, "Yes", as in the English pair, boycott - lad. In an additional 25\%, the stimulus pairs had a same meaning and pronunciation $(\mathrm{M}=\mathrm{P}=)$ (there is no English equivalent). For the remaining 50\% (40 trials) in each task, neither the meanings nor the pronunciations of a pair were same $(\mathrm{M} \neq \mathrm{P} \neq)$. An equivalent in English would be namesake - water, requiring the response "No". Thus, half the responses in each task required, "Yes" response and half required, "No". Conditions were randomized over the 80 trials. As mentioned above, there were two lists constructed on the same principles; each list was given to half the participants. One list used in one task to a subject is used in the other task to a different subject to control list counterbalance of subject and task. A list of stimuli was not replicated between the two tasks with a subject. So a pair of two lists, where stimuli of each list were different, but the conditions were remained, was prepared. Thus the experiment has two tasks. Each task has two stimulus lists. Each list has three conditions. The lists were treated between subjects and the tasks and the conditions were designed as within subject variables

All target stimuli were controlled in terms of familiarity. The Chinese characters used in Korean people were not listed in the standard tables of frequency. For checking familiarity, 30 subjects were sampled from the same population as the subjects in this experiment. They did not participate in this experiment, being similar in knowledge of the Chinese characters. They rated the familiarity of each stimulus with $1-7$ Likert scale. The mean (and $S D$ ) were analyzed for each condition in task 1 ; 4.04(1.20) for $(\mathrm{M}=\mathrm{P}=), 3.98(0.96)$ for $(\mathrm{M} \neq \mathrm{P} \neq)$ and 3.93(0.81) $(\mathrm{M} \neq \mathrm{P}=)$ or $(\mathrm{M}=\mathrm{P} \neq)$, and for each condition in task 2; 3.87 for $(\mathrm{M}=\mathrm{P}=)$, 3.94(0.84) for $(\mathrm{M} \neq \mathrm{P} \neq)$ and 3.98(0.98) for $(\mathrm{M} \neq \mathrm{P}=)$ or $(\mathrm{M}=\mathrm{P} \neq)$. In analysis of variance all main effects and interaction were non-significant.

Procedure. The presentation was programmed on a computer in E-Prime. On each trial, an asterisk (“*”) appeared in the center of the screen for $300 \mathrm{msec}$ followed by a blank screen for $500 \mathrm{msec}$. The prime was presented for $300 \mathrm{msec}$ followed by a $500 \mathrm{msec}$ blank, followed by the target word for $300 \mathrm{msec}$. Following a 'Yes' or 'No' response on the computer keyboard, the next trial began after a 2 sec pause. The participant was approximately $40 \mathrm{~cm}$ from the screen. Stimuli subtended approximately 2 degrees of arc. Each task began with 20 practice trials, during which participants' questions could be answered.

\subsection{Results and Discussion}

Mean percentage correct and reaction times are presented in Table 1 . The statistic analysis was processed by SPSS (v.21.0). For accuracy and RT were processed by analyses of variance both for subject-analysis $(F 1)$ and stimulus-analysis $(F 2)$. 
Table 1. Results for each condition in experiment.

\begin{tabular}{|c|c|c|c|c|c|c|}
\hline \multirow{2}{*}{ Task } & \multirow{2}{*}{$\begin{array}{c}\text { Prime-Target } \\
\text { Condition }\end{array}$} & \multirow{2}{*}{$\begin{array}{c}\text { Correct } \\
\text { Response }\end{array}$} & \multicolumn{2}{|c|}{ Accuracy } & \multicolumn{2}{|c|}{ RT } \\
\hline & & & Percent & $\mathrm{SD}$ & Msec & SD \\
\hline \multirow{3}{*}{ Same Meaning? } & $\mathrm{M} \neq \mathrm{P} \neq$ & No & 83 & 1.91 & 647 & 20.6 \\
\hline & $\mathrm{M}=\mathrm{P}=$ & Yes & 79.5 & 2.46 & 556 & 24.4 \\
\hline & $\mathrm{M}=\mathrm{P} \neq$ & Yes & 59.6 & 2.62 & 636 & 27.8 \\
\hline \multirow{3}{*}{ Same Sound? } & $\mathrm{M} \neq \mathrm{P} \neq$ & No & 81.7 & 1.89 & 648 & 24.7 \\
\hline & $\mathrm{M}=\mathrm{P}=$ & Yes & 78.6 & 2.48 & 543 & 21.1 \\
\hline & $\mathrm{M} \neq \mathrm{P}=$ & Yes & 72 & 2.54 & 604 & 24.8 \\
\hline
\end{tabular}

With regard to RT, analysis of variance indicated that only Condition was significant for both $F 1$ and $F 2$ : $F 1(2,72)=51.92, M S e=3753, p<.001 ; F 2(2,308)=70.76, M S e=3880, p<.001$. However, the effect of Condition was highly significant. Table 1 shows that $\mathrm{P}=\mathrm{M}=$ was faster than the other two conditions, confirmed by post-hoc t-tests. There was no significant difference between the tasks of the meaning and sound judgment. A 2 by 2 ANOVA on just the positive two conditions for both tasks supported the results of the full ANOVA. Again, the only significant effect was for Condition: $F 1(1,36)=42.70, M S e=4451, p<.0001$ and $F 2(1,152)=54.01$, MSe $=5386.94, p<.0001$.

For Accuracy, Condition was significant: $F 1(2,72)=30.77, M S e=189.78, p<.001 ; F 2(2,308)=30.29$, MSe $=.024, p<.001$. The "No" responses were generally higher than the "Yes" responses which had the un-congruency conditions (Holender, 1992). The interaction of Condition and List was significant: $F 1(2,72)=5.21$, $M S e=$ 189.78, $p<.008 ; F 2(2,308)=5.04, M S e=.024, p<.007$; also the interaction of Condition and Task was significant, $F 1(2,72)=9.73, M S e=188.53, p<.001 ; F 2(2,308)=5.71, M S e=.024, p<.004$. The three-way interaction did not approach significance. The interaction of Conditions related with List or Task was not to change the figure of Condition's main tendency. Though accuracy results produced a different picture, compared to the reaction time pattern, it is evident that lower accuracy was not related to faster latency, confirming that there was no trade-off between accuracy and speed.

For the research purposes, reaction time data are more relevant because processing times (both lexical and pre-lexical) were concerned. For RT, there was no list effect and no task main effects, and none of interaction; no interaction of Condition and List, no interaction of Condition and Task, and no interaction of Condition, List and Task, but only the significant main effect. So it is sufficient to describe the only condition effects in Table 1 and to explain the tendency related with the meaning and sound judgment tasks for the experimental purpose to analyze the intrusion of phonology and morphology. No main effect and no interaction of List confirmed the counterbalance; as described in Method (as the list of stimuli was not replicated between the two tasks with a subject. So a pair of two lists, where stimuli of each list were different, but the conditions were remained, was prepared).

Of condition effects, two "Yes" responses were faster than one "No" response both in two tasks. It is generally approved that the positive decision is terminated earlier than the negative decision (see Sternberg, 1969, for general discussion). So explained with the two positive responses in each task focused on this study's purpose, the latency delayed of " $\mathrm{M}=\mathrm{P} \neq$ " compared to " $\mathrm{M}=\mathrm{P}=$ " condition on "same meaning?" task is defined as the phonological intrusion, and as the opposite is defined as the difference between " $\mathrm{M} \neq \mathrm{P}=$ " and " $\mathrm{M}=\mathrm{P}=$ " on "same sound?" measured for the morphological intrusion. When $\mathrm{M}$ rivaled with $\mathrm{P}$ as the above two conditions, there was an intrusion into the decision process by the irrelevant dimension; processing showed intrusions from both task-irrelevant meaning and pronunciation (see Katz \& Frost 1992, for more discussion). In the result, the reaction time of " $\mathrm{M}=\mathrm{P}=$ " was shorter than that of " $\mathrm{M}=\mathrm{P} \neq$ " in the "meaning-judgment task" and $\mathrm{M}=\mathrm{P}=$ was al- 
so shorter than $\mathrm{M} \neq \mathrm{P}=$ in the sound-judgment task. This result is consistent with the study's anticipation to find both intrusions of phonology and morphology. So commented, the phonological intrusion on decision about meaning (whether the meaning between Hangul prime and Hanja target is same or different) implies that it is constrained by its phonological property. In contrast, commented on the morphological intrusion on decision about sound (whether the sound between Hangul prime and Hanja target is same or different), the process is influenced by its morphological property. Thus since the two types of intrusion were found, pair of Hangul and Hanja is suggested to have both of phonological and morphological properties.

In addition, considering some points, the Task effect was not significant between "same meaning" and "same sound". The result suggests that, whether Korean readers make judgment of meanings or pronunciation about Hanja logographs, both require equal processing time. This result would be expected if lexical access is required to determine either a word's meaning and its pronunciation when reading Hanja instead of utilizing pre-lexical (i.e., decoded) phonology. This conclusion was consistent with some of other research analyzed with only Chinese character lists (Feldman \& Siok, 1999; Perfetti, Zhang, \& Berent, 1992) and the mixed lists of Korean and Chinese (Jin, Lee, \& Lee, 2013 for Chinese people; Lee \& Lee, 2009 for Korean people).

\section{Conclusion \& Suggestion}

The process of the pair of Hangul and Hanja was featured by the differentiation of phonological and morphological intrusion. Decisions about Hanja primed by Hangul showed a morphological intrusion effect as well as a phonological one. If the experiment was designed only with Chinese character, it should show only morphological intrusion as suggested by some tests for logographic systems (Feldman \& Siok, 1999 for Chinese character; see also Jin, Lee, \& Lee, 2013 for Chinese people). Otherwise if designed only with Korean character, only phonological intrusion could be observed as suggested by some tests for alphabetic and phonemic script (Lee, Miguel, Carello, \& Turvey 2013; see also Lee et al., 2006 for similar design). The two intrusions were expected in this study's design also as Lee \& Lee (2009) which combined Hangul and Hanja of Korean even for another research purpose.

At last, it is concluded that the writing systems are categorized by not one-dimensional but two-dimensional category of phonology and morphology. What was most figural is that the intrusion effects both of phonology and morphology were observed within a writing system of Korean and designed as within subject variables. However, what needs to complete the two-dimensional schema is to test some other effects of phonology and morphology i.e. as the effect of phonological rules (see also Lee et al., 2013; Lee et al., 2006 for more discussion), and the effect of radical in Chinese character (Jin, Lee, \& Lee, 2013). More seriously, the further researches require the two-dimensional schema to be applied to other languages as Japanese, English, and etcetera. The theory exampled as orthographic depth hypothesis (Frost, Katz, \& Bentin, 1987; Katz \& Frost, 1992), regarded Serbo-Croatian as phonological letter, and Hebrew as non-phonological script, and explained the process of them only by the phonological dimension. Suggested by this study, if tested on phonological and morphological intrusion, even the scripts commented as phonological or non-phonological can show both of intrusions, but the weight of each effect is predicted as varied due to the position of a script on the two-dimensional category. It is supposed that effect of phonology or morphology, explained only with an apparent effect by one-dimensional schema is to have the reciprocal effects each of which is expressed at varied weight on two-dimensional category. In cases of comparison of multiple languages, even the analysis of simple latency and accuracy varied across languages, can be accompanied with the intrusion effects, to converge on what is expected by the two-dimensional category of phonology and morphology (Jeong, Katz, Carello, \& Lee, draft). However what is inevitable of the multiple language designs is limited to the between subject variable which may lose the power of explanation.

\section{Acknowledgements}

This research was supported by Korean National Research Foundation (NRF-2013S1A2A1A01033864):

Yang Lee ideated the design, and wrote this draft and set up theorization. Claudia Carello complemented discussions.

\section{References}

DeFrancis, J. (1989). Visual Speech: The Diverse Oneness of Writing Systems. Honolulu, HW: University of Hawaii Press. 
Feldman, L. B., \& Siok, W. W. T. (1999). Semantic Radicals Contribute to the Visual Identification of Chinese Characters. Journal of Memory and Language, 40, 559-576. http://dx.doi.org/10.1006/jmla.1998.2629

Frost, R., Katz, L., \& Bentin, S. (1987). Strategies for Visual Word Recognition and Orthographical Depth: A Multilingual Comparison. Journal of Experimental Psychology: Human Perception \& Performance, 13, 104-115.

http://dx.doi.org/10.1037/0096-1523.13.1.104

Gelb, I. J. (1963). A Study of Writing. Chicago, IL: University of Chicago Press.

Hill, A. A. (1967). The Typology of Writing Systems. In W. M. Austin (Ed.), Papers in Linguistics in Honor of Léon Dostert (pp. 25-30). Hague: Mouton.

Holender, D. (1992). Expectancy Effects, Congruity Effects, and the Interpretation of Response Latency Measurement. In J. Alegria, D. Holender, J. Junca de Morais, \& M. Radeau (Eds.), Analytic Approaches to Human Cognition (pp. 351-375). Amsterdam: North-Holland.

Jeong, J., Katz, L., Carello, C., \& Lee, Y. (draft). Difference of Orthographic Depth in Word Recognition between Korean and Chinese.

Jin, J., Lee, J., \& Lee, Y. (2013). The Phonological Process with Two Patterns of Simplified Chinese Character. Research in Language, 11, 1-15. http://dx.doi.org/10.2478/rela-2013-0005

Katz, L., \& Frost, R. (1992). The Reading Process Is Different for Different Orthographies: The Orthographic Depth Hypothesis. In Frost, R., \& Katz, L., (Eds.). Orthography, Phonology, Morphology, and Meaning, (pp. 67-84). Amsterdam: Elsevier North Holland Press. http://dx.doi.org/10.1016/S0166-4115(08)62789-2

Lee, I. (1992). The Study of Korean Orthography. Seoul: Seoul National University Press.

Lee, Y. (1995). The Test of Orthographic Depth Hypothesis with Korean Word Recognition. Ph.D. Thesis, Seoul: Seoul National University.

Lee, Y. (2003). Chapter 3: The Process of Korean Orthography. In M. Jo (Ed.). Psychology of Language (pp. 67-98). Seoul: Hakgisa.

Lee, Y. (2014). Korean Writing Systems. In Proceedings of Alvin and Isabelle Liberman Memorial Workshop: Writing Systems, Reading, and Brain Mechanisms (pp. 22-27). Storrs, CT: University of Connecticut.

Lee, Y., \& Lee, C. (2009). Non-Selective Access of Phonology by Korean-Chinese Bilinguals. Psychologia, 52, $198-208$. http://dx.doi.org/10.2117/psysoc.2009.198

Lee, Y., Moreno, M., Carello, C., \& Turvey, M. (2013). Do Phonological Constraints on the Spoken Word Affect Visual Lexical Decision? Journal of Psycholinguistic Research, 42, 191-204. http://dx.doi.org/10.1007/s10936-012-9211-9

Lee, Y., Moreno, M., Park, H., Carello, C., \& Turvey, M. (2006). Phonological Assimilation and Visual Word Recognition, Journal of Psycholinguist Research, 35, 513-530. http://dx.doi.org/10.1007/s10936-006-9027-6

Lukatela, G., Eaton, T., Sabadini, L., \& Turvey, M. T. (2004). Vowel Duration Affects Visual Word Identification: Evidence That the Mediating Phonology Is Phonetically Informed. Journal of Experimental Psychology: Human Perception and Performance, 30, 151-162. http://dx.doi.org/10.1037/0096-1523.30.1.151

Lukatela, G., \& Turvey, M. T. (1994). Visual Lexical Access Is Initially Phonological: Evidence from Phonological Priming by Homophones and Pseudo-Homophones. Journal of Experimental Psychology: General, 123, 331-353. http://dx.doi.org/10.1037/0096-3445.123.4.331

Perfetti, C. A. (2011). Reading Processes and Reading Problems: Progress toward a Universal Reading Science. In P. McCardle, B. Miller, \& J. R. Lee (Eds.), Dyslexia across Languages: Orthography and the Brain-Gene-Behavior Link (pp. 18-32). Baltimore, ML: Paul Brookes.

Perfetti, C. A., Zhang, S., \& Berent, I. (1992). Reading in English and Chinese: Evidence for a "Universal” Phonological Principle. In R. Frost, \& L. Katz (Eds.), Orthography, Phonology, Morphology, and Meaning (pp. 227-248). Amsterdam: North Holland. http://dx.doi.org/10.1016/S0166-4115(08)62798-3

Rimzhim, A. (2014). Evaluating the Orthographic Depth Hypothesis in Hindi. In Proceeding of Alvin and Isabelle Liberman Memorial Workshop: Writing Systems, Reading, and Brain Mechanisms (pp. 47-59). Storrs, CT: University of Connecticut.

Rimzhim, A., Katz, L., \& Fowler, C. A. (2013). Brāhmī-Derived Orthographies are Typologically Āksharik But Functionally Predominantly Alphabetic, Writing Systems Research, 6, 41-53. http://dx.doi.org/10.1080/17586801.2013.855618

Sternberg, S. (1969). Memory Scanning: Mental Processes Revealed by Reaction-Time Experiments. American Psychologists, 57, 421-457. 


\section{Submit or recommend next manuscript to SCIRP and we will provide best service for you:}

Accepting pre-submission inquiries through Email, Facebook, LinkedIn, Twitter, etc.

A wide selection of journals (inclusive of 9 subjects, more than 200 journals)

Providing 24-hour high-quality service

User-friendly online submission system

Fair and swift peer-review system

Efficient typesetting and proofreading procedure

Display of the result of downloads and visits, as well as the number of cited articles

Maximum dissemination of your research work

Submit your manuscript at: http://papersubmission.scirp.org/ 